\title{
Dynamic rate control changes during reactive-transport processes of serpentinization
}

\author{
RYOSUKE OYANAGI ${ }^{1}$, ATSUSHI OKAMOTO ${ }^{2}$, NORIYOSHI
} TSUCHIYA $^{3}$

${ }^{1}$ Japan Agency for Marine-Earth Science and Technology (JAMSTEC), Japan. royanagi@jamstec.go.jp

${ }^{2}$ Tohoku University, Japan. atsushi.okamoto.d4@tohoku.ac.jp

${ }^{3}$ Tohoku University, Sendai 980-8579, Japan.

noriyoshi.tsuchiya.e6@tohoku.ac.jp

Silica activity in fluids is a key factor that controls reaction pathways during the hydrothermal alteration of olivine in the oceanic lithosphere. In this study, we conducted hydrothermal experiments $\left(300^{\circ} \mathrm{C}, 8.58 \mathrm{MPa}\right)$ on the olivine (Ol)-quartz (Qtz)- $\mathrm{H}_{2} \mathrm{O}$ system to understand the coupling between silica transport and olivine alteration. Mineral powders were reacted with $0.5 \mathrm{~mol} \mathrm{~kg} \mathrm{~kg}^{-1} \mathrm{NaCl}$ solution in a tube-in-tube type vessel, and the spatial distribution of reactant and product minerals was investigated after the experiments. Alteration zones formed in the Ol-hosted region after 2055 hours of reaction. With increasing distance from the Ol-Qtz boundary these were: talc; talc + serpentine; and serpentine + magnetite + brucite. No secondary minerals formed in the Qtz-hosted region. The observed mineral distribution was modeled using a reactive transport model that simulated the coupling between $\mathrm{SiO}_{2}$ (aq) diffusion and seven silica-controlling reactions. An inverse modeling framework, which combines a reactive transport model with an exchange Monte Carlo method, was used to parameterize the diffusivity of $\mathrm{SiO}_{2(\mathrm{aq})}$ and the rate constants of the seven overall reactions. Our model shows that the rate-control process changed from being surface- to transport-controlled over the course of the experiments. We suggest that dynamic changes in rate control process are important contributors to the formation of metasomatic zoning and heterogeneous hydration patterns within the oceanic lithosphere.

\section{Reference}

Oyanagi, R., Okamoto, A., \& Tsuchiya, N. (2020). Silica controls on hydration kinetics during serpentinization of olivine: Insights from hydrothermal experiments and a reactive transport model. Geochimica et Cosmochimica Acta, 270, 21-42. 